\title{
Independence of the galvanic skin reflex from the vasoconstrictor reflex in man
}

\author{
B. J. PROUT \\ From the M.R.C. Body Temperature Research Unit, Department of the Regius Professor of Medicine, \\ The Radcliffe Infirmary, Oxford
}

The electrodermal reflex, also known as the galvanic skin reflex or the psycho-galvanic skin refiex, is a change in the skin potential (Tarchanoff, 1890) evoked by a wide range of stimuli which in turn also evoke other autonomic effects. In particular there may be a reflex vasoconstriction of the digits in man, or of the footpads in the cat, the sites where the electrodermal response is usually recorded in these species.

In the past there has been divided opinion about the relation between the galvanic skin response and the accompanying vascular response. Some have stated that the electrical response is a consequence of the vascular changes (Féré, 1888; Vigouroux, 1888; Aveling and McDowall, 1925; Densham and Wells, 1927; Carmichael, Honeyman, Kolb, and Stewart, 1941). Others have considered the galvanic skin response to be a response of the sweat glands which is independent of the vascular reaction (Tarchanoff, 1890; Veraguth, 1906; Darrow, 1929; Landis, 1932). The conflicting opinions may be the result of variable and incomplete methods of separating the responses. Lader and Montagu (1962) first achieved complete separation of the responses in man by a pharmacological blocking method showing that each may occur when the other response is blocked.

By observing continuous simultaneous records of these two responses in man, and without the necessity of obliterating either by physical or pharmacological means, it is demonstrated in this paper that the galvanic skin reflex occurs quite independently of the state of the vascular bed in the same region of the body. A parallel is drawn with observations in the cat previously reported in this journal (Prout, Coote, and Downman, 1965).

\section{MATERIALS AND METHODS}

EXPERIMENTAL PROCEDURE The subjects were six male and two female. Each subject lay on a couch within a plywood constructed annexe of the main laboratory in which the temperature was thermostatically controlled at $22-23^{\circ} \mathrm{C}$. The connexions from the patient passed through holes in the wall of the annexe to the recording apparatus housed in the main laboratory. The subject could be observed through a small window in the door of the annexe.

GALVANIC SKIN RESPONSE This response was recorded as a voltage change between two silver discs of $1 \mathrm{~cm}$. diameter. One disc with Cambridge electrode jelly on its contact face was attached to the palmar surface of the tip of the forefinger or great toe with adhesive tape, and the other indifferent electrode was attached in a similar manner to the skin of the dorsum of the same digit in the region of the proximal phalanx. Surface grease was first removed by wiping the area lightly with cotton wool dipped in acetone. Voltage changes were recorded with a Grass 5PI preamplifier (time constant $0.8 \mathrm{sec}$.).

VASCULAR RESPONSES These responses were recorded by two methods. The same finger in which the galvanic skin response was being recorded was inserted into a glass plethysmograph and an airtight seal made with cotton bandage impregnated with silicone grease wrapped around the rim. The plethysmograph was connected by polythene tubing of low distensibility via a two-way tap to a Grass PT 5A volume transducer. By means of the tap the system could be opened to the atmosphere in order to equalize the pressures on either side of the transducer diaphragm. Decreases of finger volume with decrease of amplitude of pulsation indicated vasoconstriction of the finger (Downman, Goggio, McSwiney, and Young, 1943), whilst the converse changes indicated vasodilatation.

The other method of recording the vascular change was to attach a photoelectric plethysmograph across the pulp of an adjacent finger to that placed in the glass plethysmograph. Repeated recordings previously had checked that in the conditions of this experiment similar changes occur simultaneously in adjacent fingers and that responses recorded in one finger could be taken as representative of any other finger in the same hand.

HEART RATE In some experiments the heart rate was recorded continuously with a Grass tachograph recorder which produced a tracing in which the vertical extent of the pen deflection was proportional to the heart rate. The 
greater the pen deflection the slower the heart rate and vice versa.

RECORDING INSTRUMENT The recorder was a Grass model 5 polygraph fitted with 5 DC amplifiers, a time and stimulus marker, and ink writing oscillographs. A chart speed of $1.5 \mathrm{~mm}$. per sec. was used throughout the investigations.

STIMULI Several types of stimuli evoked the responses but the most effective were found to be auditory (a metal tray dropped to the floor from a height of $60 \mathrm{~cm}$.), or the subject was instructed to inspire deeply. In addition to the reflexly evoked responses, spontaneously occurring responses were frequently observed on both records. During each experiment, therefore, the stimuli were only applied when the baselines of each tracing were level, this being when the subject was at rest. The stimuli were applied in an irregular sequence in order to minimize the effects of habituation and anticipation.
RESULTS

That it is essential to elicit the responses when the subject is mentally at rest is shown in Fig. 1 where the galvanic skin response is recorded in all four limbs of a female subject. In the first part of the record there is minimal activity in the baseline with the subject at rest; when the subject was spoken to, although she did not move, there was a marked increase in the frequency and amplitude of the spontaneous potentials which were synchronous in the four limbs; the potentials in the toes occurred slightly later than those in the fingers, presumably owing to the greater distance of the former from the central nervous system. It has previously been shown that a series of galvanic skin potentials produced by mental activity may be accompanied by prolonged vasoconstriction, and an increase in arterial blood

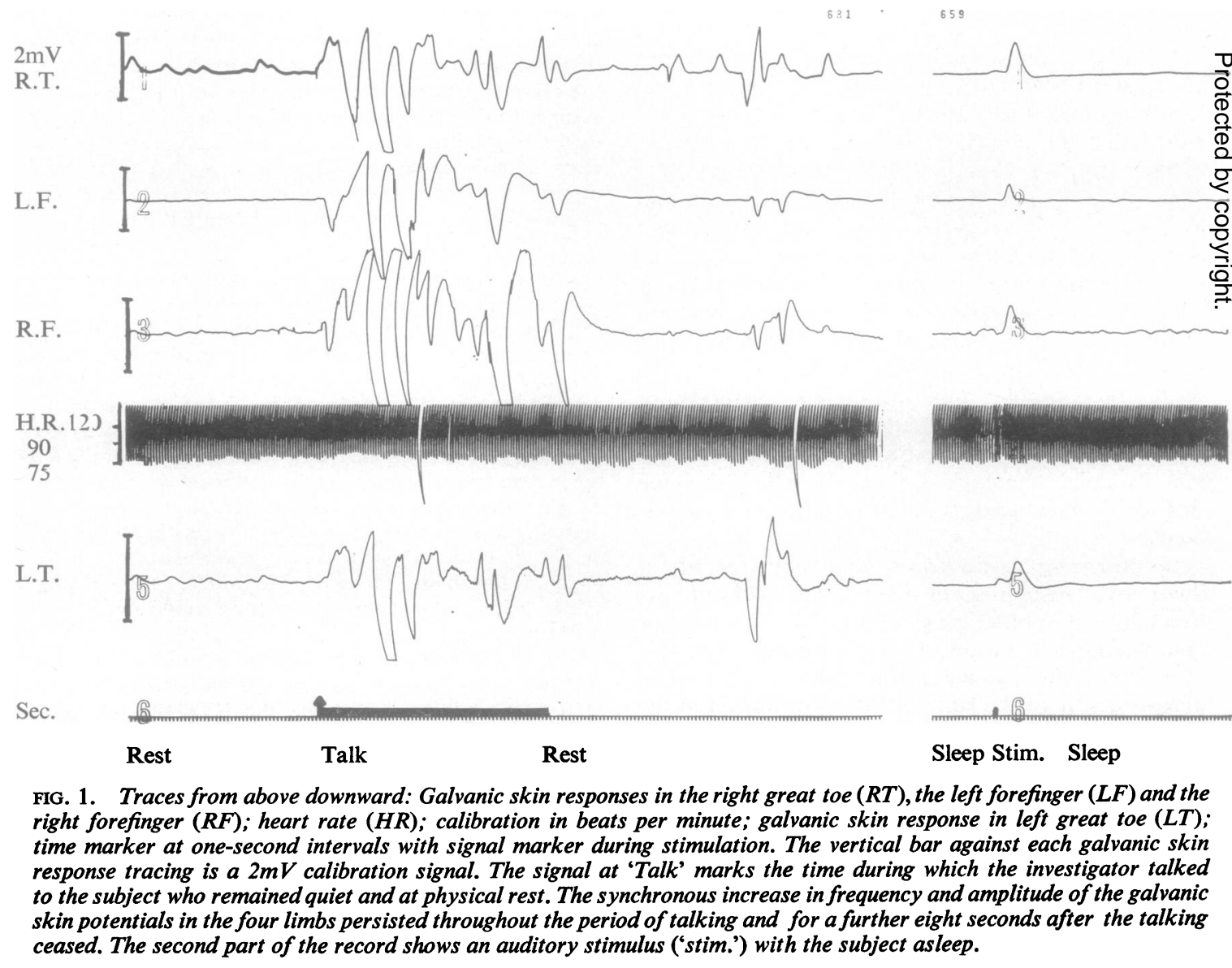




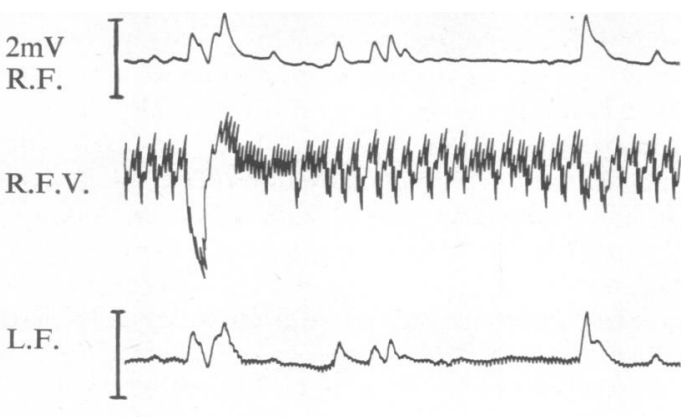

R.F.P.

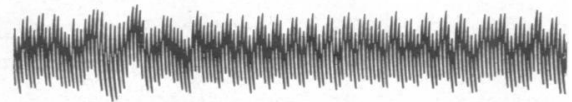

R.T.

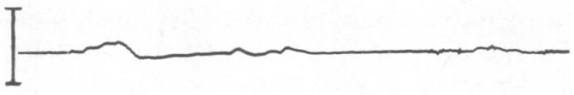

Sec.

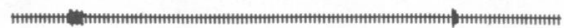

I

Sp.

B

FIG. 2. Traces from above downward: Galvanic skin response in right forefinger $(R F)$; volume change of right forefinger in glass plethysmograph (RFV), a downward movement of the trace indicating a decrease in finger volume; galvanic skin response in left forefinger $(L F)$; the amplitude of pulsations in the right middle finger (RFP) recorded with the photoelectric plethysmograph, a decrease of amplitude indicating vasoconstriction, an increase vasodilatation; galvanic skin response in the right great toe $(R T)$; time marker of one second with stimulus trace. The calibration signal of $2 \mathrm{mV}$ is shown at each galvanic skin response tracing. At ' $I$ ' the subject inspired deeply. The amplitude of pulsations in the right middle finger decreased, and increased in parallel with the changes in volume recorded in the forefinger. At 'Sp' there was a series of spontaneous galvanic skin potentials. At ' $B$ ' there was an auditory stimulus.

pressure and heart rate (see also Jung, 1954). In this subject the heart rate did not change by more than 10 beats per minute throughout the period of mental activity. After the mental stimulation had ceased the potentials continued for a further $8 \mathrm{sec}$. before the baseline flattened, and $40 \mathrm{sec}$. later there was another spontaneous discharge as a result of unidentified stimuli. The second part of the record shows an almost flat baseline with the subject asleep; in this case it is possible to see clearly the reflex response evoked by an auditory stimulus. Although it was not necessary to have the subject asleep during the observations mental rest was clearly important so that the elicited reflex responses would stand out clearly on a flat baseline.

The traces in Fig. 2 were taken from another subject and were typical of the type of responses that could be obtained. A deep inspiration produced a galvanic skin reflex in the right forefinger together with a vasoconstriction in that same finger as judged by the downward deflection of the trace and a diminution of the amplitude of the volume pulse. The pulsations in the adjacent middle finger recorded with the photoelectric plethysmograph similarly showed a decrease in the amplitude of the pulsations synchronous with the vasoconstriction in the forefinger and an increase in the amplitude of the pulsations as the finger vessels dilated again. Fifteen seconds after the inspiratory galvanic skin reflex and vasoconstrictor reflex there occurred a series of spontaneous galvanic skin potentials but there was no accompanying vasoconstriction. Similarly, later when an auditory stimulus was presented to the subject there was a prominent galvanic skin response in the finger but no vasoconstriction of the same finger.

As for the vasoconstrictor reflex, the development of a galvanic skin response is dependent upon a discharge along sympathetic nerves to the skin (Downman et al., 1943; Wang, 1957, 1958). The occurrence of a galvanic skin response in the subject at ' $\mathrm{Sp}$ ' and ' $\mathrm{B}$ ' in Fig. 2 shows that a sympathetic discharge has occurred in the sympathetic nerve pathways to the finger. The vasoconstrictor response was absent, however, on these occasions even when the amplitude of the galvanic skin response was comparable with that occurring previously with the vasoconstrictor reflex.

In the subjects studied an auditory stimulus or one deep inspiration evoked either both responses simultaneously or one response in the absence of the other. Moreover, there was no relationship between the amplitude of the responses; for instance, a large galvanic skin response may be accompanied by a large vasoconstriction, a relatively small vasoconstriction, or no vasoconstriction at all.

A distended bladder is an important factor affecting autonomic reflexes and the depressing effect of standard increments of bladder distension on the vasoconstrictor reflex and the galvanic skin reflex simultaneously elicited has been investigated in the cat (Prout, Coote, and Downman, 1964). It was therefore considered worth while ascertaining if bladder distension had any differential influence on these two reflexes in a healthy human subject. Four subjects were given a litre of water to drink and asked not to empty the bladder; the investigations 


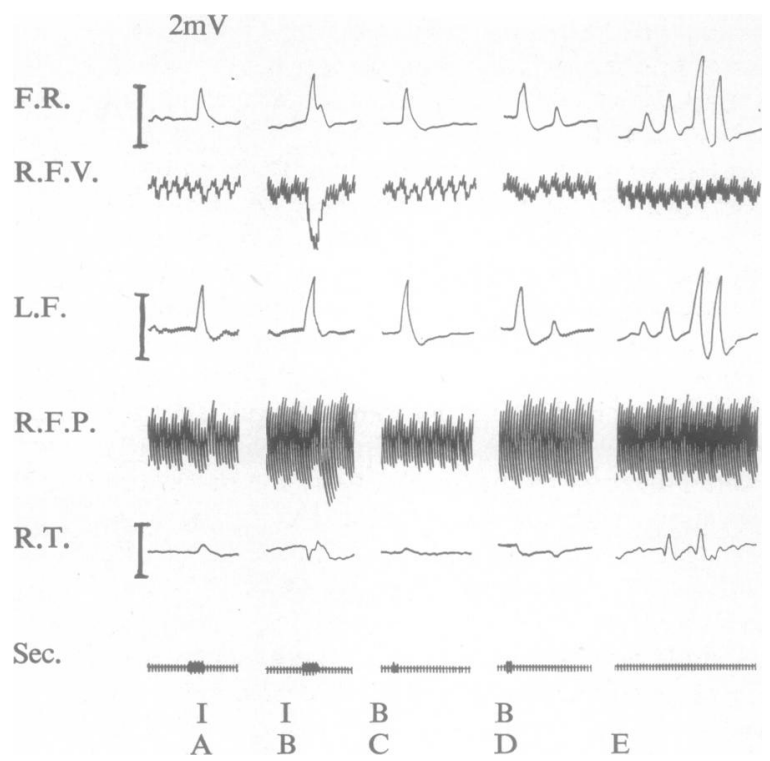

FIG. 3. Traces from above downwards as in Figure 2. In column $A$ there was a galvanic skin reflex evoked by an inspiration at ' $I$ ' but there was no vasoconstrictor reflex. In column $B$ the effect of an inspiration was repeated after the subject had voided $800 \mathrm{ml}$. of urine. Note, the increased volume pulse and the vasoconstrictor reflex. In column $C$ an auditory stimulus $(B)$ was introduced. The same stimulus was repeated after the bladder had been emptied (column D). Column $E$ shows a series of spontaneous galvanic skin potentials with no vascular change.

were then carried out two hours later. The amplitude of the reflexes was reduced in all the four subjects who were examined again when their bladders were distended. In these subjects the amplitude of the resting volume pulse was less during the period of bladder distension than after micturition. The blood vessels of the fingers during the vasoconstricted phase were, however, still capable of constriction as shown by a further decrease in the volume pulsations and change in the baseline induced by locally cooling the hand. In all the subjects it was possible to obtain an unequivocal vasoconstrictor reflex with the stimuli used only after the bladder had been emptied although a galvanic skin reflex could still be obtained. The vascular reflex was therefore more sensitive to bladder distension. In Fig. 3 a series of observations on one of the subjects is shown where the vasoconstrictor reflex was depressed during bladder distension yet the galvanic skin reflex was unchanged. At the start of the investigation while the bladder was full the subject inspired deeply and evoked a galvanic skin reflex in the limbs under study; in the right finger where the galvanic skin reflex and vascular reflex were simultaneously recorded this stimulus resulted only in one reflex, namely, the galvanic skin reflex. However, after the subject had emptied his bladder of $800 \mathrm{ml}$. of urine a similar inspiration produced both the galvanic skin reflex and the vasoconstrictor reflex. A sudden auditory stimulus produced a galvanic skin reflex both before and after emptying the bladder and although the sympathetic discharge was of the same degree as that produced by an inspiration, as judged by the equal amplitude of the galvanic skin reflexes, no vasoconstriction occurred. The other feature noted in these tracings is the increased amplitude of the pulsations in the finger after bladder emptying indicating dilatation of the skin blood vessels due to release of vasoconstrictor tone. The portion of the tracing labelled E in Fig. 3 shows a series of spontaneous galvanic skin potentials of amplitude even greater than any of the previous responses, which indicated considerable sympathetic discharge to the right finger, but there was no vasoconstriction of that finger.

\section{DISCUSSION}

A wide range of stimuli may evoke widespread reflex responses involving somatic and visceral effectors. Among these responses a vasoconstrictor reflex recorded as a change in finger volume and the galvanic skin reflex can be recorded as transient responses in the tips of fingers. These responses result from discharges along the sympathetic innervation to the fingers producing a constriction of the blood vessels, and a voltage change across the skin. In the past there has been discussion about the relationship between the electrical and vascular events. Several different workers, including Carmichael and his associates (1941) and Goadby and Goadby (1936, 1949), have proposed that the galvanic skin reflex is dependent on the synchronous development of vasoconstriction and sweating and therefore implying that these two responses occur simultaneously in the same area of the body. Prout et al. (1965) showed that these same responses can be recorded in the anaesthetized cat's footpads and that they can be elicited separately when activating the central paths by direct electrical stimulation of the brainstem using a stereotactic technique, or reflexly evoked by electrical stimulation of the central cut end of a peripheral nerve. The galvanic skin reflex in the cat can be inhibited by repetitive stimulation in the ventromedial medullary reticular formation (Wang and Brown, 1956). The reflex vasoconstrictor response can also be inhibited by similar stimulation (Prout et al., 1964). When both reflexes are recorded simultaneously then it can be 
demonstrated that they can be inhibited independently by stereotactic stimulation within the brainstem (Prout et al., 1965). Moreover the reflexly elicited responses can also be facilitated independently by brainstem stimulation (Prout, 1963). Lader and Montagu (1962) showed in man that iontophoresis of atropine abolished the galvanic skin reflex without affecting vasomotor activity, whilst bretylium introduced in a similar fashion to paralyse adrenergic nerve endings abolished vasomotor activity without affecting the galvanic skin reflex. These results imply that the post-ganglionic paths for the responses are mutually independent.

Previous observations on the anaesthetized cat showed that over a period of several hours the same standard sensory stimulus evoked either both reflexes simultaneously, one reflex in the absence of the other, or no reflexes at all. It seemed that if a normal human subject were studied over a long period and that one could see a similar variation in the responses then there would be no need to produce differential blockade, as performed by Lader and Montagu (1962), to demonstrate their separability. A convenient way of demonstrating the dissociation between peripheral vascular and galvanic skin responses is to use the finger plethysmograph (Prout et al., 1965; Lader and Montagu, 1962). It should be emphasized that alterations in volume of the extremity recorded in this way do not necessarily imply a corresponding change in blood flow; however, it is only the relation between the galvanic skin reflex and the overall or net vascular smooth muscle tone of the region which is in question.

Analogous findings to those obtained in cat experiments were found. Two factors in particular were found to influence the type of response obtained in the cat. The first was the plane of anaesthesia; the galvanic skin reflex was generally obtained at a lighter level of anaesthesia than that required for the vasoconstrictor response to appear. The second was the degree of bladder distension, the reflexes being depressed in the presence of a distended bladder (Prout et al., 1964, 1965; Guttmann and Whitteridge, 1947). In the observations reported in this paper on healthy subjects a distended bladder depressed both the galvanic skin reflex and the vasoconstrictor reflex, the latter reflex being most sensitive. In view of the close similarity between the observations of these two autonomic reflexes in the cat and man, it would seem not unreasonable to extend the conclusions drawn from the cat experiments to suggest that a distended bladder in man depresses the autonomic reflexes by occlusion rather than by true inhibition. However, as true inhibition of the responses can occur in the cat by activity in downward projecting supraspinal pathways acting at the level of the spinal reflex arcs, and since there are spinal autonomic reflexes in man (Gilliatt, Guttman, and Whitteridge, 1948), a similar inhibitory pathway probably exists in man.

Whether the vasoconstrictor reflex or the galvanic skin reflex is depressed by the effect of occlusion or inhibition it seems clear that they are influenced separately, and the independence of the responses evoked as reflexes suggests that they have separate pathways at the segmental level. Moreover, the independence of these two autonomic activities in the same area of the periphery suggests that there is a similar fractionate control over the autonomic nervous system as there is in the somatic nervous system.

\section{SUMMARY}

The galvanic skin reflex and the vasoconstrictor reflex have been recorded on the same digit of healthy subjects at rest.

The reflexes may fluctuate independently in size and one reflex may occur in the absence of the other.

A distended bladder may result in depression of one reflex without influencing the other.

The experimental results have been discussed in the light of previous observations in the cat.

It is concluded that in man vascular and sweat gland responses in the same area of skin can function independently of each other, and have separate nervous pathways.

The author wishes to thank Professor Sir George Pickering and Dr. K. E. Cooper for their encouragement.

\section{REFERENCES}

Aveling, F., and McDowall, R. J. S. (1925). The effect of the circulation on the electric resistance of the skin. J. Physiol. (Lond.), 60, 316-321.

Carmichael, E. A., Honeyman, W. M., Kolb, L. C., and Stewart, W. K. (1941). A physiological study of the skin resistance response in man. Ibid., 99, 329-337.

Darrow, C. W. (1929). The galvanic skin-reflex and finger volume changes. Amer. J. Physiol., 88, 219-229.

Densham, H. B., and Wells, H. M. (1927). The mechanism by which the electrical resistance of the skin is altered. Quart. J. exp. Physiol., 18, $175-184$.

Downman, C. B. B., Goggio, A. F., McSwiney, B. A., and Young, M. H. C. (1943). Reflex vaso-motor responses of the paw of the cat. J. Physiol. (Lond.), 102, 216-227.

Féré, C. (1888). Note sur les modifications de la résistance electrique sous l'influence des excitations sensorielles et des émotions. C.R. Soc. Biol. (Paris), 40, (8 ser. 5), 217-219.

Gilliatt, R. W., Guttmann, L., and Whitteridgs, D. (1948). Inspiratory vaso-constriction in patients after spinal injuries. J. Physiol. (Lond.), 107, 67-75.

Goadby, K., and Goadby, H. (1936). Simultaneous photographic records of the potential and resistance effects of the psychoemotive response. Ibid., 86, 11-13 P.

- (1949). The nervous pathway of the psycho-galvanic skin reflex. Ibid., 109, 177-184.

Guttmann, L., and Whitteridge, D. (1947). Effects of bladder distension on autonomic mechanisms after spinal cord injuries. Brain, 70, 361-404. 
Jung, R. (1954). Correlation of bioelectrical and autonomic phenomena with alterations of consciousness and arousal in man. In Brain mechanisms and consciousness. A Symposium organized by the Council for International Organizations of Medical Sciences, pp. 310-344. Blackwell, Oxford.

Lader, M. H., and Montagu, J. D. (1962). The psycho-galvanic reflex: A pharmacological study of the peripheral mechanism. $J$. Neurol. Neurosurg. Psychiat., 25, 126-133.

Landis, C. (1932). Electrical phenomena of the skin. Psychol. Bull., 29, 693-752.

Prout, B. J. (1963). Supraspinal control of direct and reflex actions of the autonomic nervous system. Ph.D. Thesis, University of London.

- Coote, J. H., and Downman, C. B. B. (1964). Supraspinal inhibition of a cutaneous vascular reflex in the cat. Amer. $J$. Physiol., 207, 303-307.

$\longrightarrow,-$, (1965). Independence of central controls of vascular and sweat gland responses in the paw of the cat. J. Neurol. Neurosurg. Psychiat., 28, 223-227.

Tarchanoff, J. (1890). Ueber die galvanischen Erscheinungen in der Haut des Menschen bei Reizungen der Sinnesorgane und bei verschiedenen Formen der psychischen Thätigkeit. Pflugers Arch. ges. Physiol., 46, 46-55.

Veraguth, O. (1906). Die Verlegung diaskleral in das menschliche Auge einfallender Lichtreize in den Raum. Z. Psychol., 42, 162-174.

Vigouroux, R. (1888). L'électricité du corps humain. C.R. Soc Biol. (Paris), 40, (8 ser. 5,) 138-142.

Wang, G. H., (1957). The galvanic skin reflex. A review of old and recent works from a physiologic point of view. Part I. Amer. J. phys. Med., 36, 295-320.

(1958). Part 2. Ibid., 37, 35-57.

- , and Brown, V. W. (1956). Supraspinal inhibition of an autonomic reflex. Ibid., 19, 564-572. 